\title{
Experimental Organism Luteinized Unruptured Follicle
}

National Cancer Institute

\section{Source}

National Cancer Institute. Experimental Organism Luteinized Unruptured Follicle. NCI

Thesaurus. Code C123640.

A corpus luteum-like structure with a retained oocyte and variably luteinized granulosa cells. 